\title{
Hungry Listening: Resonant Theory for Indigenous Sound Studies
}

\author{
Dylan Robinson
}

London and Minneapolis: University of Minnesota Press, 2020

ISBN 9781517907693

\section{Marie Thompson \\ The Open University \\ Marie.thompson@open.ac.uk}

Dylan Robinson's Hungry Listening: Resonant Theory for Indigenous Sound Studies begins with the words of R. Murray Schafer. Writing in 1961, Schafer derides "the Eskimos" as "an astonishingly unmusical race", to the extent that "the composer really has to wring his material to make it musically presentable. There is a marked similarity between an Eskimo singing and Sir Winston Churchill clearing his throat." (Schafer quoted In Robinson, 2020: 1). This derogation of Inuit throat singing is important in situating the arguments pursued in Robinson's important and original book. Hungry Listening is a critical response to the whiteness of sound studies - a field in which Schafer remains influential. This opening epigraph also makes apparent the Canadian context of this text. While the sensory logics discussed are applicable to other settler colonial territories, Robinson's primary focus concerns Canada's colonial history and musical culture. The invocation of compositional violence by Schafer ("wringing" Inuit material) and desire for "presentability", meanwhile, exemplifies Robinson's central thesis: that Indigenous participation in the settler domains of classical and contemporary music, musicals and popular music has too often been guided by an aspiration on the part of the latter for aesthetic assimilation. Attempts to "include" Indigenous sound performance often discount and devalue the ontologies and protocols to which they are attached.

There are two connected thematic strands around which Hungry Listening is structured: the relationships between Indigenous sound practices and Western art music, and the relationships between listening, positionality and settler colonialism. Robinson's concept of "hungry listening", from which the book takes its title, names an Indigenous understanding of a settler colonial perceptual logic. I found Robinson's articulation of how listening can be grounded in - and serve to 
reproduce - harmful relations of domination, dispossession and inequality particularly pertinent, since capacious listening is often uncritically celebrated as ethically and aesthetically virtuous. Derived from two Halq'eméylem words shxwelitemelh (the adjective for a settler or white person's methods or things, and comes from the word xwelitem referring to white settlers, or, more precisely "starving person") and xwélalà:m (the term for listening) - hungry listening concerns an extractivist orientation towards the world. As Robinson notes, this pairing of words is uncomfortable: "xwélalà:m points toward a xwélmexw-specific sensory orientation, while shxwelitemelh explicitly identifies a non-Indigenous sensory orientation" (2). However, in juxtaposing these Indigenous and non-Indigenous sensory modes, Robinson "seeks to acknowledge the current reality of many if not most Indigenous people at various points of perceptual in-between" (3). Consequently, Robinson suggests that shxwelítemelh xwélalà:m is more appropriately thought in terms of positionality rather than pertaining to a (white) racial identity: for Robinson "identity is a cohesive fact, while positionality is a 'shifty' state"' (237).

Responding to "the dramatic increase of Indigenous participation in art music since the early 1990s across a variety of forms and artistic media" (3), Robinson examines the "politics of aesthetics" that subtends what he defines as "inclusionary music" (6). Partly symptomatic of Canadian recognition politics, which posits inclusion as central to "good relations", inclusionary music may, on the surface, sound progressive. However, it is predicated on a fixation on Indigenous "content" as opposed to "structure", and representation as opposed to redefinition. As a counterbalance to "inclusionary music", Robinson proposes an alternative mode of relation: "Indigenous+art music". This designation emphasises incompatibility, irreconcilability, sovereignty and resistance to integration contra assimilation, unity and hybridity. It also acknowledges the foundational differences between Indigenous and Western approaches to music and song.

These foundational differences are central to Chapters One and Two. The first chapter, "Hungry listening", reflects upon settler and Indigenous listening positionalities. The disjuncture between Indigenous and settler ontologies is illustrated with reference to the land claim trial of the Gitxsan and Wet'suwet'en peoples, Delgamuukw v. the Queen (1985). The plaintiff's council had asked the witness, Chief Mary Johnson, to recite a Gitksan song as part of her evidence. The requested limx oo'y (dirge song) was a historical account and, in its Indigenous context, could function as a legal order. However, the presiding judge, Justice McEachern, refused to hear the song as such, responding that "this is a trial, not a performance" (43). The comments of the trial's judge make clear his inability or unwillingness to comprehend song as something other than an aesthetic encounter.

Chapter Two: "Writing about musical intersubjectivity" considers Indigenous epistemologies alongside non-representational theory and new materialism to address how performative writing can challenge "the dichotomy between music's limited agency as a passive 'object', and the listener as active partner" (79). With reference to the artistic work of Peter Morin (Tahltan) and Tanya Lukin Linklater (Alutiiq), Robinson notes how Indigenous artists have sought to address "the museum as a carceral space" by using song and music to reconnect with cultural belongings that have been seized and erroneously displayed as objects. These belongings are not objects at all: "they have life, they are living beings, or they are ancestors" (87). For Robinson, an "apposite methodology" of writing, which conveys the affective, sensory and intersubjective relationships with music, song 
and space can help expand music scholarship, unsettle normative disciplinary formations and uphold Indigenous epistemic values.

Musical and artistic case studies in Chapters Three, Four and Five explicate "inclusionary" music practices that affirm Canadian, liberal democratic notions of reconciliation, tolerance and multiculturalism. Chapter Three: "Contemporary encounters between Indigenous and early music", addresses the increasingly prevalent tendency for Indigenous and settler composers to juxtapose pre-1750 European art music and Inuit and First Nations cultural practice in a restaging of the sound worlds of "first contact". Robinson contrasts compositional approaches that aim toward an aesthetics of integration and are grounded in "the Canadian myth of peaceful encounter between First Peoples and settlers" (129); with Indigenous+Early Music approaches that maintain "the rough edges of difference" (143). Chapter Four: "Ethnographic redress and compositional responsibility" addresses ethnographic practices of recording and transcriptions of Indigenous song and their use within inclusionary art music, as well as by Indigenous artists.

Chapter Five: "Feeling reconciliation" turns to address inclusionary music's reception through a powerful examination of live concert audiences' affective responses to three music events presented as part of the Vancouver 2010 Cultural Olympiad: the rock musical Beyond Eden, the "powwow-bhangra-electronic music" performance Different Drum (202), and the dance performance Hannah and the Inukshuks. Drawing on his own experiences as a spectator and utilising methods of performative writing discussed in Chapter Two, Robinson offers a compelling critique of a shared, reconciliatory affect that "conflates a collapse of distance with a collapse of difference" (205) by foregrounding how ostensibly shared physiological responses such as crying and ovation can "have strikingly different efficacies for Indigenous and settler audience members" (202). The chapter clearly illustrates the limitations of investing in the affective power of music to enact positive transformation. As Robinson concludes:

It is not enough to embrace the mystery of difference. It is not enough to let the embrace of sound surround. It is necessary to move beyond the position of intergenerational bystanders. It is necessary to acknowledge the privilege and power that we hold within our artistic and working communities, and then find ways to give over such power that move beyond forms of inclusion. (222)

One of the most striking aspects of Hungry Listening is its politics of form. Unfolding over the course of the five chapters, which are interspersed with a series of event scores, Robinson's decolonial critique is grounded in a mixture of voices, rhetorical strategies, theoretical models, historical accounts, dialogues and poetics. The emphasis on Indigenous sovereignty and the refusal of hungry listening's extractivist logics are manifest in a section of the Introduction, which is written exclusively for Indigenous readers. Non-Indigenous, settler, or xwelítem readers such as myself - are asked not to read this part of the book. In the conclusion, Robinson offers space to two settler ethnomusicologists - Deborah Wong and Ellen Waterman - "to 'work out amongst themselves' what decolonial listening might entail" (239). Intended to complement the Introduction's space for Indigenous sovereignty, Wong and Waterman's dialogue is described as remaining in the format of 'working it out'. I found this section a little frustrating; however, on reflection, this frustration was partly symptomatic of my own problematic expectations for neat concluding remarks or the provision of next steps. The challenge of listening otherwise cannot be resolved in a few pages. 
The temptation is to end this review in a standard fashion by summarising to whom this book will be of interest and what types of scholar will find it useful. Yet to situate Robinson's book in such a manner risks reproducing the settler logic of hungry extraction that he rightfully seeks to foreground, critique and counter: it risks presenting his work as a resource to be mined by different academic communities. Indeed, I wonder about the extent to which I have already participated in this logic, by attempting to provide an accessible summary of key arguments, themes and examples. I find myself pulled in different directions by, on the one hand, the (settler) expectations attached to scholarly knowledge production and, on the other, the insights offered by Robinson about settler modes of engagement. The felt irreconcilability between the two is a testament to Hungry Listening's significance, as well as a reminder of the work that needs to be done. 